\title{
Relation of high CA125 and CA19-9 levels with recent rupture of endometrioma
}

\author{
Murat Gözüküçük • Salih Taşkın • Tolga Taşcı • \\ Murat Sönmezer • Cem Atabekoğlu
}

Received: 21 March 2011 / Accepted: 14 April 2011 /Published online: 3 May 2011

(C) Springer-Verlag 2011

\begin{abstract}
Most of endometriomas with CA125 level over $1,000 \mathrm{IU} / \mathrm{mL}$ have related with rupture. This is important in differential diagnosis from malign ovarian disease. However, the mechanism of elevation of CA125 in patients with endometrioma is not clear. We reviewed elevation of CA125 level over 1,000 IU/mL in endometriomas and attempted to explore possible mechanisms of this elevation together with presentation of our current case. A review of the literature suggests that extremely elevated CA125 level combined with high CA19-9 level may indicate a recent rupture of endometrioma.
\end{abstract}

Keywords Endometrioma - Laparoscopy $\cdot$ Rupture · CA125 - CA19-9

\section{Introduction}

CA125, recognized by the monoclonal antibody OC 125 , is an antigen marker of a high molecular weight glycoprotein and it is the most eligible tumor marker for epithelial ovarian carcinomas of coelomic cell origin. Serum CA125 concentration may also be moderately elevated in advanced endometrial and cervical adenocarcinomas and several

\footnotetext{
M. Gözüküçük · S. Taşkın • T. Tașc1 • M. Sönmezer •

C. Atabekoğlu

Department of Obstetrics and Gynecology,

Ankara University Medical Faculty,

Ankara, Turkey

M. Gözüküçük (ه)

Ankara Universitesi Tip Fak,

Kadin Dog,

AD 06100 Cebeci, Ankara, Turkey

e-mail: muratgozukucuk@gmail.com
}

benign conditions such as pelvic inflammatory disease, uterine fibroids, and especially in endometriosis [1].

Although there has been an increasing number of case reports that ovarian endometrioma and advanced endometriosis may be associated with extremely elevated serum CA125 levels, patients with endometriosis have rarely CA125 concentrations $>100 \mathrm{U} / \mathrm{mL}$ [2]. The American College of Obstetricians and Gynecologists suggested that patients with a pelvic mass and CA125 level above the $200 \mathrm{IU} / \mathrm{mL}$ should be considered for referral or consultation with a gynecological oncologist [3]. However, in the last two decades, there is an increase in the number of reports associating unusually high CA125 level over $1,000 \mathrm{IU} / \mathrm{mL}$ in patients with endometriosis (Tables 1 and 2). Another tumor marker, CA19-9, is essentially elevated in gastrointestinal system malignancies. Although malignant and benign ovarian disorders may cause elevation, it rarely increases above $1,000 \mathrm{U} / \mathrm{mL}$ in endometriosis [4]. In this review, endometrioma cases with high levels of CA125 and CA19-9 were evaluated and the relation between the rupture of endometriomas and these markers was discussed.

\section{Clinical presentation}

A 25-year-old nulligravida was referred to the emergency department with a history of intense lower abdominal pain accompanied by nausea and vomiting. She was observed in emergency service due to suspicion of acute abdominal pain. She was transferred to our clinic on the second day of admission. Her menstrual cycles were regular and she was on tenth day of her 30-day cycle. There was no gynecological disorder in her past medical history. Physical examination upon admission revealed bilateral lower quadrant tenderness, and ultrasound showed a large loculated $5 \times 4 \times 4.5 \mathrm{~cm}$ cyst in 


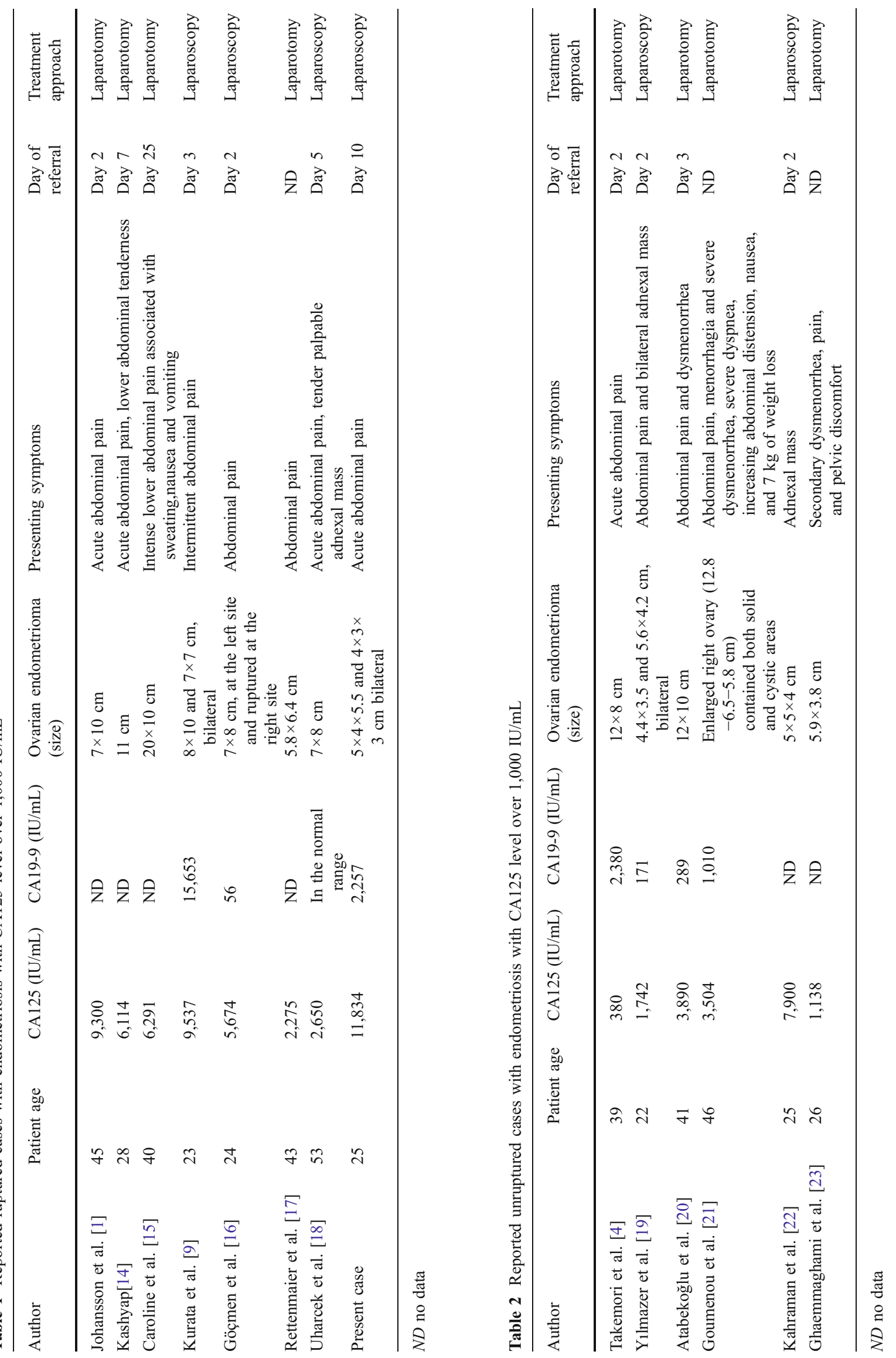


the left adnexal region and a $4 \times 3 \times 3 \mathrm{~cm}$ hypoechoic mass with diffuse low-level internal echoes in the right adnexal region. Abdominopelvic computed tomography confirmed the findings of ultrasonography. A full blood count, renal and liver function tests, as well as beta hCG, CA125, and CA19-9 were ordered. Urine analysis and chest $\mathrm{X}$-rays were also ordered. All the blood works were within the normal limits except for an elevated white cell count of 15,900 cells $/ \mu \mathrm{L}$, serum CA125 of $11,834 \mathrm{IU} / \mathrm{mL}$, and serum CA19-9 of 2,257 IU/mL. CA125 and CA19-9 levels were measured by using appropriate chemiluminescent micro particle immunoassay kits (Abbott Diagnostics, Abbott Park, IL)

The patient was observed for 6 days because of the regression of symptoms. There was no difference in ultrasonographic findings between the first visit and preoperative evaluation. Ca125 and Ca19-9 levels were 5,273 and $737 \mathrm{IU} / \mathrm{mL}$, respectively, before the surgery. Laparoscopic surgery was performed on day 8 of admission. It revealed a ruptured endometrioma on the right ovary and an intact cyst on the left ovary. Thick brown fluid from the right ruptured cyst entirely covered the peritoneum. Additionally, most parts of the intestinal and peritoneal surfaces, as well as omentum, were covered by diffuse endometriotic implants. Bilateral ovarian cystectomy and partial omentectomy were performed and peritoneal washings were taken. Histopathology confirmed the diagnosis of endometrioma. The patient was discharged uneventfully on the third postoperative day. Depot GnRH analogue goserelin acetate, (Zoladex, Astra Zeneca, Istanbul, Turkey) was started $3.6 \mathrm{mg} /$ month postoperatively for 2 months. CA125 and CA19-9 levels reduced to $28.95 \mathrm{IU} / \mathrm{mL}$ and $33.31 \mathrm{IU} / \mathrm{mL}$, respectively, in 2 months and the treatment was continued with combined oral contraceptives.

\section{Discussion}

Endometiromas are rarely seen with extremely high level of CA125. Rupture presence in most of the cases with CA125 level over $1,000 \mathrm{IU} / \mathrm{mL}$ suggested the relation between extremely high level of this marker and rupture of endometiroma. In addition to CA125 level, CA19-9 level could also be found high.

One immunohistochemical study has shown that although the degree of positive staining showed considerable variation, all of the endometriotic lesions were positive for CA125 [5]. Another immunohistochemical study demonstrated that the glandular epithelial cells in the ovarian chocolate cyst were stained intensely with the anti-CA19-9 antibody in almost three quarters of the specimens [6]. This difference may explain why some cases presented only an extremely high level of CA125 without high levels of CA19-9.

\section{What is the mechanism of elevation of CA125 and CA19-9 in ruptured endometriomas?}

The fluid of endometrioma may contain high level of CA125 and CA19-9 molecules and diffusion of this fluid through the peritoneal surface into the circulation may cause extremely elevated serum CA125 and CA19-9 concentrations. Koninckx et al. reported that the CA125 concentration in the cyst fluid of an ovarian endometrioma may exceed $1 \times 10^{6} \mathrm{IU} / \mathrm{mL}$ [7]. According to the authors, the thick wall of the endometriotic cyst prevents the large CA125 glycoprotein molecules from reaching the peripheral circulation [8]. Kurata et al. reported the highest CA125 serum level of $9,537 \mathrm{IU} / \mathrm{mL}$ in a ruptured endometrioma, which was confirmed by histological analysis as well [9]. In that case, the serum CA19-9 level was $15,653 \mathrm{IU} / \mathrm{mL}$ and CA125 and CA19-9 levels in the peritoneal fluid were 160,000 and $208,192 \mathrm{IU} / \mathrm{mL}$, respectively. Kurata et al. proposed that after the rupture of the endometrioma, the cyst fluid spilled into the peritoneum and ascites-serum exchange may cause extremely elevated serum levels of CA125 and CA19-9. An enlarged surface area of endometrial tissue may contribute to the elevated levels of CA125 [10]. We speculated that measuring CA125 and/or CA19-9 in the peritoneal fluid could be offered for the confirmation or differential diagnosis of a ruptured endometrioma in cases with very high serum levels of CA125 or CA19-9. Table 1 summarizes ruptured endometriomas with CA125 level up to $1,000 \mathrm{IU} / \mathrm{mL}$.

\section{Mesothelial cells as a CA125 source}

There is evidence that peritoneal mesothelial cells are even more potent than ovarian cancer cells in producing CA125 [11]. The irritation of the peritoneal surface as a result of the rupture of the endometriotic cyst probably causes a major part of excess CA125 in the circulation [12, 13]. Johansson et al. presented a case with extremely elevated CA125 levels whose highest level was seen 4 days after the onset of the symptoms, but persistence of pathological CA125 levels for 4-5 months support the concept that mesothelial cells of the peritoneum were the most important source of CA125 in that case [1].

The CA125 level in our case was $11,834 \mathrm{IU} / \mathrm{mL}$, which is the highest value reported thus far in a ruptured endometrioma. In the current case, we measured serum CA125 3 days after symptoms appeared, and we think that associated inflammatory reaction of the mesothelial cells of the peritoneum due to endometrioma rupture may be a strong contributing factor to this highest value.

CA19-9 is localized in the glandular epithelial cells in endometriotic cysts in many patients with endometriosis [6]. CA19-9 level was also found extremely high as $2,257 \mathrm{IU} / \mathrm{mL}$ in presented case. Because no evidence exists 
regarding the production of CA19-9 by peritoneal mesothelial cells, the same hypothesis cannot be put forward to explain high CA19-9 level. We believe that an increase in serum CA19-9 levels is caused by the spillage of chocolate cyst fluid along with rupture or diffusion of this molecule through a thin-walled cyst to the peritoneum.

\section{Unruptured endometriomas and high CA125 levels}

Although extremely high levels of serum CA125 were reported in patients with unruptured endometriomas, initial symptoms and intraoperative findings of these patients resemble each other; we assume that high level of CA125 in unruptured endometriomas is pointing out a previous rupture. Almost in all cases, patients had abdominal pain at the time of hospital admittance, and the pelvic peritoneal surfaces, omentum, and uterus were covered with diffused endometriotic foci at the time of the laparoscopy. All of these cases presented in the follicular phase, especially during the menstruation. Unruptured endometriomas with CA125 level up to $1,000 \mathrm{IU} / \mathrm{mL}$ is demonstrated in Table 2.

\section{Conclusion}

Endometriomas may be with extraordinary high CA125 and/or CA19-9 levels. Rupture of endometriomas has been demonstrated in most of these cases. Although it required more number of data, endometiromas should be kept in mind in differential diagnosis from malignancy in the cases with very high level of CA125 and CA19-9.

Conflicts of interest The authors report no conflicts of interest. The authors alone are responsible for the content and writing of the paper.

\section{References}

1. Johansson J, Santala M, Kauppila A (1998) Explosive rise of serum CA125 following the rupture of ovarian endometrioma. Hum Reprod 13:3503-3504

2. Kauppila A, Telimaa S, Rönnberg L, Vuori J (1988) Placebocontrolled study on serum concentrations of CA-125 before and after treatment of endometriosis with danazol or high-dose medroxyprogesterone acetate alone or after surgery. Fertil Steril 49:37-41

3. ACOG Committee on Gynecologic Practice (2003) The role of the generalist obstetrician-gynecologist in the early detection of ovarian cancer. Int J Gynaecol Obstet 80:235-238
4. Takemori M, Sugimura K (1991) Ovarian chocolate cyst with markedly elevated serum CA19-9 level: a case report. Eur J Obstet Gynecol Reprod Biol 42:241-244

5. Toki T, Kubota J, Lu X, Nakayama K (2000) Immunohistochemical analysis of CA125, CA19-9, and Ki-67 in stage III or IV endometriosis: positive correlation between serum CA125 level and endometriotic epithelial cell proliferation. Acta Obstet Gynecol Scand 79:771-776

6. Harada T, Kubota T, Aso T (2002) Usefulness of CA19-9 versus CA125 for the diagnosis of endometriosis. Fertil Steril 78:733-739

7. Koninckx PR, Muyldermans M, Moerman P, Meuleman C, Deprest J, Cornillie F (1992) CA125 concentrations in ovarian 'chocolate' cyst fluid can differentiate an endometriotic cyst from a cystic corpus luteum. Hum Reprod 7:1314-1317

8. Koninckx PR, Riittinen L, Seppala M, Cornillie FJ (1992) CA125 and placental protein 14 concentrations in plasma and peritoneal fluid of women with deeply infiltrating pelvic endometriosis. Fertil Steril $57: 523-530$

9. Kurata H, Sasaki M, Kase H, Yamamato Y, Aoki Y, Tanaka K (2002) Elevated serum CA125 and CA19-9 due to spontaneous rupture of endometrioma. Eur J Obstet Gynecol Reprod Biol 105:75-76

10. Barbieri RL (1987) CA125 and endometriosis. Contracept Gynecol Obstet 16:103-108

11. Zeimet AG, Marth C, Offner FA et al (1996) Human peritoneal mesothelial cells are more potent than ovarian cancer cells in producing tumor marker CA125. Gynecol Oncol 62:384-389

12. Barbieri RL, Niloff JM, Bast RC Jr, Scaetzl E, Kistner RW, Knapp RC (1986) Elevated serum concentrations of CA125 in patients with advanced endometriosis. Fertil Steril 45:630-634

13. Bouquet de Jolinière J, Validire P, Canis M, Doussau M, Levardon M, Gogusev J (1997) Human endometriosis-derived permanent cell line (FbEM-1): establishment and characterization. Hum Reprod Update 3:117-123

14. Kashyap RJ (1999) Extremely elevated serum CA125 due to endometriosis. Aust NZ J Obstet Gynaecol 39:269-270

15. Caroline C, Bashir T (2002) Exceptionally high levels of CA125 due to endometriosis. J Obstet Gynaecol 22:329-330

16. Göçmen A, Karaca M, Tarakçioğlu M (2003) A ruptured ovarian endometrioma mimicking ovarian malignancy: case report. Eur J Gynaecol Oncol 24:445-446

17. Rettenmaier MA, Goldstein BH, Stallman JM, Brown JV, Micha JP (2005) Greatly elevated serum CA125 Level in a patient with a ruptured endometrioma. J Gynecol Surg 21:117-120

18. Uharcek P, Mlyncek M, Ravinger J (2007) Elevation of serum CA125 and D-dimer levels associated with rupture of ovarian endometrioma. Int J Biol Markers 22:203-205

19. Yilmazer M, Sonmezer M, Gungor M, Fenkci V, Cevrioglu S (2003) Unusually elevated serum carbohydrate antigen 125 (CA125) and CA19-9 levels as a result of unruptured bilateral endometrioma. Aust N Z J Obstet Gynaecol 43:329-330

20. Atabekoglu CS, Sönmezer M, Aydinuraz B, Dünder I (2003) Extremely elevated CA125 level due to an unruptured large endometrioma. Eur J Obstet Gynecol Reprod Biol 110:105-106

21. Goumenou A, Matalliotakis I, Mahutte N, Koumantakis E (2006) Endometriosis mimicking advanced ovarian cancer. Fertil Steril 86(219):e23-e25

22. Kahraman K, Ozguven I, Gungor M, Atabekoglu CS (2007) Extremely elevated serum CA125 level as a result of unruptured unilateral endometrioma: the highest value reported. Fertil Steril 88(968):e15-e17

23. Ghaemmaghami F, Karimi Zarchi M, Hamedi B (2007) High levels of CA125 (over 1,000 IU/mL) in patients with gynecologic disease and no malignant conditions: three cases and literature review. Arch Gynecol Obstet 276:559-561 